\title{
Da prática ao ensino: a constituição da clínica odontológica
}

\author{
Cristine Maria Warmling*
}

* Programa de Pós-graduação em Ensino na Saúde, UFRGS; Programa de Pós-graduação em Avaliação de Tecnologias para o SUS, Grupo Hospitalar Conceição

Recebido em 31/08/2017. Aprovado em 17/11/2017.

\section{RESUMO}

O objetivo do estudo é analisar relações estabelecidas entre práticas profissionais e ensino odontológico na constituição da clínica odontológica no contexto de aproximação e separação da Medicina no Brasil. Foram analisadas diferentes fontes documentais: legislação, atas institucionais, documentos jornalísticos e jurídicos, relatórios governamentais, assim como livros técnicos e históricos do campo da Odontologia. A intenção é usar a história para problematizar a atualidade. Verificou-se que a clínica odontológica, no seu processo de constituição, se aproximou e até se confundiu com a técnica e com a prótese dentária, tanto nas práticas profissionais como no ensino. Um modo de funcionar presente nas práticas discursivas de profissionais, no início do século XX, separou a Odontologia da Medicina e representou, não apenas prescindir dos conhecimentos e procedimentos intrínsecos à clínica médica, mas direcionou, também, seu contexto científico e de criação. O processo de instituição do ensino de Odontologia em separado do da Medicina, no Brasil, desempenhou, aí, um papel preponderante.

Descritores: Ensino. História. Odontologia. Saúde Bucal. Clínicas Odontológicas.

\section{INTRODUÇÃO}

Mais do que o abandono de velhas teorias e sistemas é o olhar que assume um estatuto na análise foucaultiana sobre a emergência da clínica médica moderna - as formas de visibilidade mudaram ${ }^{1}$. A relação do olhar médico com o seu objeto (o corpo humano adoecido) se transformou.
$\mathrm{O}$ que se tornou imprescindível na nova experiência do saber médico quando fundou a clínica, foi a ligação que se estabeleceu entre o olhar e a linguagem. A experiência clínica, este acontecimento capital da relação do homem consigo mesmo e da linguagem com as coisas ${ }^{1}$. Olhar é nomear na clínica médica. 
Mas, e no caso da Odontologia, questionase, que clínica embasou o nascimento da profissão? ${ }^{2}$. Entre o olhar e a linguagem, na clínica odontológica, pode-se dizer que estará sempre presente o dente determinando o processo de autonomização da boca em relação à pessoa. Teria a clínica odontológica se furtado de conhecimentos sobre o homem? Ou, teria a prática odontológica prescindido da clínica médica? ${ }^{2}$ Pois, Fauchard é considerado pai da Odontologia, ainda no início do século XVIII, anteriormente ao nascimento da clínica médica, acontecimento ocorrido apenas no fim do século XIX ${ }^{3}$. À época $a$ clínica médica ainda não havia adquirido nem a emergência nem a visibilidade que a constituiriam como tal apenas um século depois ${ }^{2}$.

Em quais circunstâncias fundou-se a clínica odontológica, técnica, autonomizada e distante dos saberes do homem e da sociedade? Quais conhecimentos e práticas tornaram possível o tipo e o modo do saber e do fazer clínico odontológico?

O que está em jogo, ao se suspeitar da emergência da clínica odontológica, colocando em cheque o reconhecimento da paternidade "fauchardiana", não é a maior ou menor cientificidade dos discursos que se fizeram sobre boca e dentes, mas os interesses que se impuseram na construção social da prática odontológica. Neste sentido, pode-se dizer que não foi um apelo, ou científico, ou prático, que teria estimulado a separação da Odontologia da Medicina, mas o estabelecimento de um tipo muito específico de prática odontológica que, ao se consolidar, impôs a separação.

Seria a Odontologia ciência ou seria prática? A defesa de que a Medicina é em primeiro lugar uma técnica, baseia-se no fato de que antes mesmo de ser ciência o conhecimento médico é inteiramente desenvolvido na esperança de que o estado indesejável e depreciativo que constitui a doença possa ser previsto, melhorado, curado ou pelo menos aliviado de alguma forma ${ }^{4}$. Os âmbitos da ciência e da prática não devem ser vistos em oposição, pois estão em continuidade.

A história da tradição da Odontologia é formada por ícones (Fauchard), por invenções (a anestesia), por instituições (a revista, a associação, a escola) e por tecnologias. Veja-se, por exemplo, o caso do pequeno e fundamental instrumento clínico que caracteriza a prática e guia a clínica odontológica - o espelho dental. Instrumento e referência simbólica da profissão, tal como o estetoscópio para a Medicina. O espelho dental, a tecnologia que revolucionou o olhar do dentista. Quase uma extensão da mão no trato com a boca e os dentes. O seu uso especificou o olhar do dentista, fazendo-o perseguir os mais precoces sinais de anormalidade bucais. Com o espelho dental, o olhar do dentista potencializou a capacidade de vigilância, tornando visível o que lhe escapava no recôndito de dentes e da boca: as cicatrículas e fissuras, as bordas das restaurações, as interproximais, as colorações dentais e gengivais, etc. $\mathrm{O}$ espelho dental regula parâmetros de examinar normalidades e patogenicidades. Será necessário frear a visibilidade incontida do espelho tendo em vista a proliferação dos ciclos restauradores repetitivos, pois, na história do espelho dental para a Odontologia, olhar é sinônimo de restaurar.

Essas relações todas - ciência e técnica, Medicina e Odontologia, ofício e profissão, formados e práticos, boca e dentes, dentre outras marcam não apenas o modo como ocorreu a conformação da clínica odontológica, mas principalmente as mudanças de sentido que foram sendo operadas nas práticas odontológicas e de ensino, para se produzir identidade ao cirugião- 
dentista. Pois constituíram, por meio de diferentes exigências sociais, continuidades e descontinuidades nas concepções e conceitos profissionais, técnicos e científicos que produzem a subjetividade do cirurgião-dentista e, portanto, da clínica que realiza.

O panorama descrito fundamenta o objetivo do estudo que é analisar relações estabelecidas entre práticas profissionais e ensino odontológico na constituição da clínica odontológica no contexto de aproximação e separação da Medicina no Brasil.

\section{METODOLOGIA}

Os interesses das análises históricas realizadas por esse estudo, que busca compreender a clínica odontológica, voltam-se para a forma como esse saber pôde ter se constituído, suas condições de possibilidade e os efeitos que produziu. Foram colocados em relação saberes e práticas em seus processos históricos. Verificouse, por exemplo, o que significou para a Odontologia, para a Medicina e para a sociedade estabelecer a autonomia profissional. As exigências históricas que constituíram a clínica odontológica estão relacionadas aos processos de instituição do ensino odontológico, base científica e prática da profissão e, por conseguinte, da clínica odontológica.

Foram analisadas diferentes fontes documentais: legislação, atas institucionais, documentos jornalísticos e jurídicos, relatórios governamentais, assim como, livros técnicos e históricos do campo da Odontologia.

A intenção ao realizar estudos históricos sobre a prática e a clínica odontológica é aproximar-se de análises sobre o papel de um tipo muito específico de estudo histórico, que é aquele que está voltado para o presente - o "historiador do presente", ou que se dispõe a dizer a atualidade a partir da análise do passado ${ }^{5}$. Diagnosticar as práticas odontológicas da atualidade a partir de sua constituição histórica assemelha-se a um ato de decomposição das certezas que unem a Odontologia ao presente. Não é uma crítica à Odontologia a se fazer, mas trata-se de verificar suas condições de formação. Fazer aparecer o que está perto, o que é tão imediato, o que está tão intimamente ligado a nós mesmos que exatamente por isso não o percebemos [...] fazer ver o que vemos ${ }^{1}$.

\section{DA INFECÇÃO DENTÁRIA ÀS DOENÇAS GERAIS: A CLÍNICA COMO EXODONTIA}

As práticas discursivas, no início do século XX, de três autores brasileiros referencias no ensino e na profissão de Odontologia - Souza, $(1927)^{6}$; Lima, (1929) ${ }^{7}$ e Schifino, (1956) ${ }^{8}$ destacam o que se estabelecia à época para a relação entre o foco infeccioso dentário ou bucal e a saúde geral. Analisando as obras dos autores é possível problematizar, não apenas o modo como se delineava no início da constituição da profissão e do ensino no Brasil as relações entre Medicina e Odontologia, mas a própria clínica odontológica.

A prática profissional de Lima (1929), professor do Curso de Odontologia da Faculdade de Medicina e Farmácia de Porto Alegre ${ }^{9}$, está registrada no livro Da Odontologia à Medicina. $\mathrm{O}$ livro abordou um tema com certa repercussão à época: a relação entre Odontologia e Medicina ${ }^{7}$. A obra possibilita verificar de que modo um dentista/professor problematizou tais relações no início do Século XX. O autor denuncia o descuido de dentistas com a propedêutica e a semiologia.

$\mathrm{Na}$ observação que se vai ler, há afirmativas denunciadoras de imperdoáveis descuidos de técnica propedêutica. Por causa desses deslizes explicáveis pela 
pressa com que examinam os dentes e pelo mau hábito de só se considerar enfermos os que são visivelmente lesados, a paciente, a que vamos nos referir, relembrou, pesaroso, o indiferentismo, a desatenção, com que lhe examinaram os dentes dois colegas patrícios ${ }^{7}$.

Interessou-se pela explicação da patogenia da infecção focal causada pelos elementos dentários. À época os conhecimentos sobre bacteriologia eram incipientes o acesso ao uso de antibióticos na clínica diária era muito limitado o que justifica a preocupação com a propagação de focos de infecção. Usando referências de autores da década de 1920 da língua inglesa, alguns franceses e muito poucos na língua portuguesa ou espanhola, afirmou: Não há doença que se restrinja ao local. As desordens patológicas locais, embora aparentemente circunscritas a uma parte limitada do organismo suscitam sempre reações adversas gerais ${ }^{7}$. Desenvolveu estudos sobre as relações existentes entre a infecção dentária e problemas com a saúde geral.

A infecção dentária pode ser considerada como elemento perturbador do equilíbrio ácido básico. É digno de nota o paralelismo que existe entre o índice de alcalinidade e a taxa do íon cálcio no sangue [...] A infecção dentária pode agir direta ou indiretamente sobre o aparelho de visão [...] Inúmeras pesquisas de laboratório, que a clínica confirma, demonstram que é, efetivamente, notável a influência da infecção dentária, na etiologia das nefrites $[\ldots]^{7}$

Posteriormente, na segunda edição do livro (1939) $)^{10}$, com o título ajustado para Odontologia e Medicina justificou que não há caminho algum a fazer da Odontologia à Medicina. Foram registrados comentários positivos de diversas e representativas publicações nacionais, tanto da área da Medicina quanto da Odontologia.

Ainda não está longe e não raros os que ainda pensam que cuidar de dentes, se não é pura preocupação estética pode apenas beneficiar à mastigação. Pois no presente trabalho o autor demonstra, com a melhor documentação desejável, a influência que as infecções dentárias exercem nos domínios da hematologia, do metabolismo geral e especialmente do cálcio, nos diversos aparelhos, em várias funções glandulares, em repercussões intensas e decisivas. [...] Mas a Odontologia, em qualquer de seus ramos, não passa de um ramo da Medicina e não é possível ser hoje um bom dentista sem ser também um bom médico. Do contrário não passará de um artífice. $[\ldots]^{10}$

Observa-se que para os casos descritos por Lima $^{7}$ a solução odontológica era simples e na maioria das vezes se resumia à indicação da extração do dente, que compreendido como foco infeccioso originário do problema médico, deveria ser removido.

Felizmente, depois disso, as melhoras se acentuaram continuamente, a ponto de se poder afirmar que a saúde mental da paciente ficou completamente restabelecida, seis ou oito meses depois de extraídos os dentes impactados. Atualmente, ela raciocina com toda a clareza [...] O exame bacteriológico da urina revelou infecções estafilocócica. Dois dentes infectados foram extraídos. As melhoras do paciente foram imediatas, por isso que, dentro das primeiras 24 horas, desapareceram os sintomas indicativos de inflamação 
vesical. E o fim de duas semanas, já ele podia reter a urina por mais de cinco horas ${ }^{7}$.

A explanação das questões médicas e gerais nos casos parecia servir, antes, para justificar a própria prática odontológica (a exodontia) do que para potencializar soluções que integrassem práticas médicas e odontológicas. A exodontia enquanto resposta técnica/local/odontológica aos problemas de ordem geral, gerava incapacidade de integração das práticas odontológicas e médicas.

Souza $^{6}$ foi um profissional reconhecido que se destacou na emergência da Odontologia brasileira $^{11}$. Escreveu um livro de grande abrangência nacional (Manual Odontológico) com primeira edição datada de 1917, mas reeditado inúmeras vezes em anos posteriores. Viajou aos Estados Unidos para representar o Brasil perante o $7^{\circ}$ Congresso Dentário de Filadélfia, em 1926. Ao regressar publicou uma obra contendo o relato completo da viajem (Impressões dos Estados Unidos) e na mensagem de agradecimento aos queridos amigos cita Lima ${ }^{6}$. No congresso, assistiu a conferência intitulada $O$ s dentes em relação com a saúde geral, com temática coincidente à descrita em Lima ${ }^{7}$. A teoria focal é de fácil compreensão, [...]. A lesão local causada, por exemplo, pela picada de uma agulha infeccionada, provoca uma lesão que pode generalizar-se. [...] Se isto é exato, como não admitir que infecções dentárias, [...] não se estendam também a outros pontos do organismo? ${ }^{6}$.

Trinta anos depois, Schifino $(1956)^{8}$, instrutor de Ensino da segunda cadeira de Clínica Odontológica da Escola de Odontologia de Porto Alegre, publicou um artigo no primeiro número da revista do então já autônomo Curso de Odontologia (A infecção focal de origem bucal). $\mathrm{O}$ termo bucal amplia a compreensão da origem da infecção focal, concebendo-a como não mais apenas dentária, mas bucal, ou seja, podendo esta infecção ser proveniente de tecidos periodontônticos, focos periapicais (raízes ou infecção residual) e polpa viva infectada ${ }^{8} \quad \mathrm{O}$ autor retomou o tema da discussão proposta por Lima em seus dois livros ${ }^{7-10}$.

O problema da infecção focal de origem bucal agitou por muito tempo os meios científicos trazendo uma série imensa de controvérsias, discutindo-se muito e criando-se sérias divergências a seu respeito [...] Sempre reinou e, talvez reina grande confusão no que respeita infecção focal de origem bucal. Mas não há dúvida que, levando em conta o conceito exato de organismo, considerando-o como um todo formado de partes com vital interdependência, e funcionando com uma perfeição que jamais será igualada por qualquer máquina construída pelo homem engenhoso, devemos admitir a possibilidade da instalação da infecção focal tendo como origem um foco de infecção origem bucal ${ }^{8}$.

Conceituou infecção focal como um foco instalado em determinada parte do organismo que pode desenvolver outro foco à distância, em outra parte do organismo. Quando ocorre, isto é, quando devido a um foco primário desenvolvemse lesões secundárias, diz-se que se instalou uma 'infecção focal' . Para Schifino, houve um critério clínico exagerado quanto ao perigo dos focos de infecção apicais como desencadeadores de infecção focal, levando ao 'extracionismo', muitos dentes foram condenados e removidos sem necessidade alguma ${ }^{8}$. Uma conduta terapêutica acertada diante de um foco de infecção bucal com provável relação com outra parte do organismo 
deveria embasar-se em três critérios: (1) no conceito bacteriológico (2) critério biológico (3) sentido clínico ${ }^{8}$.

A conferência que Souza $^{6}$ assistiu sobre esse tema no $7^{\circ}$ Congresso Dentário de Filadélfia, foi proferida por um autor referenciado também em Schifino $^{8}$, o médico e pesquisador Rosenow. A tese desse autor comprovando a relação entre infecções dentárias e gerais se baseava em experiências biológicas, onde inoculava microorganismos colhidos de focos dentários em coelhos ou ratos. Estas experiências, depois, se comprovaram em grande parte inábeis, conforme Schifino $^{8}$ relatou em seu artigo.

$\mathrm{O}$ que se pretende visibilizar aqui é de que modo esse debate pode demonstrar discursos e práticas em torno de um problema envolvendo inter-relações entre práticas odontológicas e médicas.

As argumentações de que o foco infeccioso dentário era potencial causador de infecções generalizadas eram usadas não apenas como justificativa para a realização da extração dentária, mas também combatiam o uso de técnicas pulpares inovadoras que objetivavam conservar dentes sem extraí-los.

Está provado que muitos doentes melhoraram dos seus males, logo depois de extraídos os dentes infeccionados. $O$ valor da ablação das amídalas, na cura e na prevenção das moléstias, está hoje completamente admitido. Assim o alivio de certas doenças, depois e removida a afecção dentária causal tornou-se também evidente.[...] Os dentes sem polpa poderão não trazer perturbação alguma saúde geral, durante muito tempo, mas não será para admirar, se de um para outro momento, ignorada a razão, venham a converter-se em focos ativos, exercendo ação deletéria em órgãos de eleição. $\mathrm{ODr}$. Rosenow opina que a neoformação de tecido ósseo, revelada na radiografia, depois da amputação do ápice radicular ou depois do tratamento anticéptico pelo canal, não prova que as áreas circundantes a raiz tenham ficado estéreis. O conferencista que é médico acrescentou: os clínicos americanos pararam na mecânica. Só se cuida do restabelecimento da função, conservando o dente e nada mais ${ }^{6}$.

Analisando o relato de Lima (1929) ${ }^{7}$ sobre o tema em questão, contextualizado pelos relatos de Souza $(1927)^{6}$ e de Schifino (1956) ${ }^{8}$, infere-se que o desconhecimento que havia sobre o modo de a infecção afetar o dente ou dentes e expandir-se ao organismo, relacionava-se ao desconhecimento sobre o funcionamento da patologia do órgão dental e sua relação com o organismo. Ou, também, que o desenvolvimento de conhecimento microbiológico sobre a patologia dentária no organismo, se subsumia à presença da técnica exodôntica, que se apresentava como solução rápida e prática ao problema, mesmo que dolorosa e mutiladora. Encontrando-se, desde Lima (1929) ${ }^{7}$, a preocupação com a constituição de um método clínico, com o objetivo de estabelecer relações das patologias e fisiologias gerais do organismo originárias de patologias no elemento dentário, o apelo prático da técnica exodôntica, no entanto, superava esse tipo de pensamento, possibilitando e moldando uma clínica odontológica separada da médica.

\section{A CLÍNICA ODONTOLÓGICA DA MECÂNICA BUCAL}

Lucraríamos muito mais, digamos de passagem, que se confiasse a um só catedrático o ensino da anatomia, da fisiologia e da histologia 
gerais, para desdobrar, por exemplo, a prótese em três cadeiras distintas, regidas por especialistas consagrados na matéria. Essa é a opinião de Souza $(1932)^{12}$ em seu livro Manual Odontológico: prótese dentária dentaduras. A obra de Souza, intitulada Manual Odontológico, é composta por cinco diferentes volumes, que representam um compêndio do conhecimento odontológico brasileiro do início do século XX. Os volumes do Manual Odontológico possuem os seguintes títulos: Anatomia, Histologia, Patologia Geral e Higiene, com 502 páginas e 194 figuras; Patologia Dentária e Terapêutica Aplicada, 504 páginas e 197 figuras; Prótese Dentária Dentaduras, 434 páginas e 500 figuras; e, por último, o volume intitulado Clínica Odontológica (Técnica), com 607 páginas e 433 figuras, sendo que este último possui o professor Antonio Dias de Carvalho, também de Juiz de Fora, como coautor ${ }^{12}$.

Trazer à cena histórica descrita no estudo, conceitos apresentados na obra de Souza ${ }^{12}$, permite relacionar o modo como práticas discursivas profissionais estavam sendo cunhadas, e, portanto, como, nos interstícios da conformação do ensino e da prática, se dava a separação das práticas odontológicas das médicas.

A preocupação em definir a clínica odontológica apareceu logo nas primeiras páginas do volume do Manual Odontológico: clínica odontológica, que Souza escreveu em parceria com Carvalho $^{13}$. O título desse volume - Clínica Odontológica (Técnica) — possibilita um trocadilho entre as palavras clínica e técnica, que aponta um problema conceitual encontrado no próprio livro, detectado também nas proposições curriculares dos Cursos de Odontologia nos anos seguintes. O trocadilho, jogo ou troca de palavras, representa o desafio da profissão ao tentar definir sua concepção de clínica. Técnica odontológica é sinônimo de clínica odontológica? Ou há uma técnica odontológica na clínica odontológica, mas esta última se resume à primeira?

Para definir a clínica odontológica, Carvalho e Souza $(1917)^{13}$ utilizam os dois movimentos protagonizados pela profissão em relação à Medicina, no campo da clínica odontológica: o movimento de separação e o movimento de integração entre práticas médicas e odontológicas, movimentos realizados a um só tempo.

Integração, pois, segundo os autores, para definir o que é clínica odontológica é preciso saber antes o que é clínica médica.

A clínica geral, médica ou cirúrgica, consiste em reconhecer as diversas moléstias ou afecções que acometem o corpo humano, e instituir-lhes um tratamento judicioso, de acordo com os progressos da ciência, [...] a clínica odontológica consiste em reconhecer as diferentes afecções de que são suscetíveis os órgãos constituintes do aparelho dentário e partes imediatamente anexas $e$ tratá-las pelos meios mais modernos que a ciência atualmente aconselha ${ }^{13}$.

Separação, pois a clínica odontológica, na consideração dos autores, seria então a aplicação prática dos conhecimentos de patologia $e$ terapêutica dentárias. Alertam, porém, que não se deva supor, que para concretizar os objetivos da clínica odontológica, seja necessário dilatar a sua esfera de ação, levando as suas intervenções aos outros órgãos além dos da região gengivodentária; não é necessário estender os domínios do dentista, porquanto as afecções dos órgãos desta região, já pela sua frequência, já pela sua delicadeza das intervenções que exigem, e mesmo pela dificuldade de execução que estas apresentam em muitos casos, são suficientes, elas 
só, para absorverem toda a atenção e ocuparem toda a atividade de um profissional, podendo por isso o tratamento exclusivo destas afecções constituir uma especialidade a parte $e^{13}$.

A configuração final da obra de Carvalho e Souza $(1917)^{13}$ é resultado das opções dos autores de priorização e sequenciamento de temas da clínica odontológica. Da definição de que clínica se tratava à descrição do modo de fazê-la funcionar. Começando pela semiologia, que consiste em, primeiro, determinar o diagnóstico ou a natureza da patologia, que pode ser médica ou cirúrgica. Em se tratando de moléstias que se prendem a patologia interna, o diagnóstico será médico, será cirúrgico, se estas moléstias se prenderem a patologia externa ${ }^{13}$. Depois, em estabelecer o prognóstico dessa patologia identificada, qual seja a sua marcha, duração $e$ desfecho ${ }^{13}$. Para estabelecer o diagnóstico, é necessário que sejamos metódicos no pesquisar os vários sinais: lançar mão do exame físico, interrogatório exploratório, de inspeção, de palpação, de sondagem, de percussão do paciente, sendo condição essencial que o paciente seja colocado em uma posição apropriada na cadeira de operações ${ }^{13}$.

Para dar ao paciente a posição apropriada a intervenção que ele vai sofrer, colocá-loemos em uma cadeira construída para esse fim pelas fábricas de instrumentos dentários e denominada cadeira de operações. As escolas dentárias devem, pois, possuir para o seu serviço clínico somente as cadeiras apropriadas. A substituição destas por outras que não preencham os requisitos necessário traria o mal irreparável de fazer os seus alunos adquirirem o hábito de posições viciadas, que, de um certo modo, os torna incapazes para o exercício profissional ${ }^{13}$.

A maioria das intervenções praticadas pelo dentista está relacionada ao combate da cárie. Por isso mesmo, o aparelho dentário constitui o campo mais importante ou o campo por excelência das nossas intervenções ${ }^{13}$. Isto justifica dizer que $u m$ conhecimento profundo de todas as particularidades anatômicas do órgão dentário é, para o cirugião-dentista, de uma importância incalculável: arcadas dentárias, espaços interdentários, oclusão dos dentes, dentes permanentes, caracteres comuns dos dentes coroa, colo, raiz - e caracteres particulares dos dentes $^{13}$. Para que se concretize a clínica, faltaria apenas o jogo de instrumental apropriado: espelho bucal, sonda dentária, separadores, lentes, lâmpada elétrica bucal, escavadores, seringa com água tépida e água fria, fios de seda frouxa, injetor de ar, refletor ${ }^{13}$. A técnica do exame odontológico está assim descrita pelos autores:

Sentado o paciente na cadeira, e dispostos na mesinha auxiliar todos os instrumentos e material de que vamos precisar, passaremos ao exame da sua boca, depois de termos observado atentamente o seu estado geral. Em primeiro lugar fazemos um exame rápido da boca para verificar o estado das gengivas, da mucosa em geral e do aparelho dentário. Por esta primeira parte do exame, ficaremos conhecendo quais os cuidados que o paciente tem com sua boca, qual a qualidade do seu meio bucal e qual a qualidade dos seus dentes coeficiente de resistência dos seus tecidos. Depois disto faremos um exame demorado de cada um dos órgãos dentários. Ficaremos então conhecendo a natureza, a 
sede e a extensão das lesões que tem acometido a cada um deles ${ }^{13}$.

Sem esquecer que todas as lesões constatadas pelo exame da boca devem ser cuidadosamente anotadas em livro apropriado, constituindo-se a ficha dentária do indivíduo ${ }^{13}$. Estas são as informações das páginas introdutórias da obra de Carvalho e Souza ${ }^{13}$, mas a maior parte do livro é composta pelas informações que se seguem, relacionadas às técnicas de restauração dos dentes. A Técnica Odontológica propriamente dita possui temas prioritários: classificação de cavidades dentárias, substâncias obturadoras, profusão de instrumentais e não poderia deixar de estar presente a extração de dentes.

Complementa-se, ainda, a descrição das práticas discursivas na emergente clínica odontológica do início do século $\mathrm{XX}$, com as concepções sobre a boca contidas no volume do Manual Odontológico, denominado Prótese Dentária Dentaduras. O autor reserva um capítulo para apresentar as Funções da Boca. Nesse histórico sobre a emergência da autonomia do ensino da Odontologia, considerou-se pertinente relacionar o modo como se conformavam concepções sobre o órgão bucal e as práticas odontológicas.

Em Souza (1932) ${ }^{12}$, as funções fisiológicas da boca são descritas a partir da definição de sua localização anatômica.

A cabeça, anatomicamente, divide-se em crânio e face. $O$ crânio encerra os órgãos que desempenham as elevadas funções do pensamento [...] A face é o cenário da expressão, o reflexo dos sentimentos. [...] A boca concorre para a expressão fisionômica, pela sua grande mobilidade, mas as funções que o protético encara com interesse são as da mastigação e da

$$
\operatorname{dicção} o^{12} \text {. }
$$

Entre a razão e a emoção, a boca realiza uma função que é a da mastigação. As Funções do Dentes estão direcionadas à realização da ação da mastigação. Se faltam, urge substituí-los ${ }^{12}$. A ação da mastigação, função prioritária da boca, é compreendida como uma mecânica. Essa é a fisiologia da cavidade bucal que emerge pelas mãos da Odontologia neste período.

\section{A dentição permanente comporta trinta e} dois órgãos, tendo funções partícularizadas e forma apropriada a cada uma delas. Os incisivos cortam, os caninos dilaceram, este ato modificado pelas regras da civilidade, os pré-molares dividem e os molares trituram os alimentos apreendidos. [...] Os dentes implantam-se nos alvéolos dos dois maxilares. [...] Tanto nos dentes superiores como nos inferiores as raízes guarnecem-se de um aparelho articular - o pericemento. [...] O maxilar inferior representa o papel de alavanca do terceiro gênero. [...] O maxilar inferior, no desempenho de seus atos fisiológicos, o da mastigação com especialidade executa vários movimentos: abaixamento, elevação, propulsão, retropupulsão $e$ diducção ${ }^{12}$.

A compreensão da mastigação enquanto mecânica ocorre através de comparações sobre o funcionamento da mastigação em outros animais. O carnívoro, o ruminante, o herbívoro, o roedor, chegando-se ao homem, animal omnívoro que, pela variada natureza de sua alimentação, exige movimentos precedentes, combinados e coordenados $^{12}$. Nos estudos da conformação da face são estabelecidas suas medidas, seus ângulos, suas linhas, e estes estudos se interligam aos da fisiologia dentária. O objetivo, o pano de fundo, o 
ponto de chegada e de partida para a compreensão da fisiologia bucal é a confecção da prótese dentária, das dentaduras. Os tipos de faces e tipos de arcadas dentárias determinam temperamentos: tipo bilioso - dentes fortes, grandes, angulosos, com pouco transpasse; temperamento nervoso dentes pequenos, claros, mais compridos, com trespasse pronunciado; temperamento sanguíneo: dentes fortes, mais largos do que compridos, com pouco trespasse ${ }^{12}$. Faces e dentes precisam ser identificados, esquadrinhados e medidos, tornando-se, assim, médias, para serem melhor reproduzidos pelos aparelhos protéticos.

\section{OS CURRÍCULOS E O ENSINO DA CLÍNICA ODONTOLÓGICA NA EMERGÊNCIA DA SEPARAÇÃO DA ODONTOLOGIA E DA MEDICINA}

Foi nos últimos anos do Império que emergiu oficialmente o ensino da Odontologia no Brasil, através da publicação do Decreto Lei $\mathrm{n}^{\circ}$ 7.247 , de 19 de abril de $1879^{14}$, propondo o Ensino da Cirurgia Dentária na forma de curso anexo da Faculdade de Medicina. A denominação do curso anexo de Cirurgia Dentária foi modificada cinco anos mais tarde para curso anexo de Odontologia, pelo Decreto n ${ }^{\circ} 9.311$, de 25 de outubro de $1884^{15}$. A proposição dessas políticas inseria-se na pauta dos problemas e debates sobre o ensino nacional, ao final do Império, podendo-se destacar duas questões: o ensino livre e prático.

Edler $(1992)^{16}$, ao analisar as reformas do ensino médico ao final Império, destaca que, naquele momento de proposição de um novo modelo de organização e funcionamento para as Faculdades de Medicina, havia a articulação entre o ensino livre e prático, com a nova representação do saber médico, que ocorria pelo deslocamento do modelo anatomoclínico para a noção de
Medicina experimental. Esses debates eram postos em jogo e constituíam as proposições políticas voltadas à organização do ensino médico.

O modelo da Medicina experimental se impunha nas proposições políticas do momento, por exemplo, pelo número de laboratórios criados pelas diretrizes da reforma do ensino de Leôncio de Carvalho. As diretrizes constituíam os laboratórios em local privilegiado para o ensino prático. A Lei Orçamentária $\mathrm{n}^{\circ} 3.141$, de 30 de outubro de 1882, legislou, entre outras coisas, sobre o financiamento para a criação de quatorze laboratórios nas Faculdades de Medicina do Império, instituindo que cada laboratório deveria ter um preparador, dois ajudantes que serão alunos da faculdade de Medicina, e um conservador. $\mathrm{O}$ décimo terceiro laboratório denominava-se de cirurgia e prótese dentária ${ }^{17} . \mathrm{O}$ laboratório para a área de cirurgia dentária, denominado em 1879, de Operações e Prótese Dentária; depois, na política orçamentária de 1882, foi denominado de Cirurgia e Prótese Dentária, passando a se chamar Prótese Dentária apenas dois anos mais tarde ${ }^{15}$.

O distanciamento das práticas dentárias das médicas foi uma das condições para a instituição do ensino da cirurgia dentária em separado da Medicina, ainda no Império. As pautas e propostas de conteúdos profissionais, contidas nas políticas que compõem a reforma Leôncio de Carvalho, de 1879, delinearam oficialmente, pela primeira vez no Brasil, o perfil do profissional para atuar com as práticas dentárias em separado das médicas. Mas, de que modo se conforma esse distanciamento preconizado inicialmente na Reforma Leôncio de Carvalho?

E, talvez, a mais evidente observação que se possa fazer neste sentido é a ausência da clínica nas proposições curriculares do Curso de 
Odontologia. Nos currículos, constam: Patologia, Histologia, Fisiologia, Cirurgia, Prótese, Terapêutica e até Higiene; mas a Clínica ficou reservada aos cursos médicos: clínica médica, clinica psychiatrica, clínica das moléstias syphiliticas e da pelle, clínica ophthalmologica ${ }^{14}$. Não há Clínica Dentária ou Clínica Odontológica. Referindo-se à Odontologia, apenas Cirurgia e Prótese Dentárias, denotando a compreensão de que na emergência da prática odontológica o conhecimento clínico parecia não possuir aplicabilidade.

O que caracteriza a oficialização e institucionalização do ensino da Odontologia em separado da Medicina, no decreto de 1884, é a inclusão de dois conteúdos nada diretamente biológicos ou humanos, tais como química e física. Estes conteúdos - Física e Química elementar assumem, posteriormente, um papel de destaque no desenvolvimento da prática odontológica restauradora, essencialmente fundamentada nas pesquisas com materiais dentários.

O aumento de um ano na duração do curso anexo de Odontologia, concomitante à inclusão de dinâmica de seriação nos exames das matérias, foram as mudanças preponderantes preconizadas no Decreto de 1884, em relação ao de 1879. Parece difícil identificar, através delas, motivos que justifiquem uma mudança de denominação de curso anexo de cirurgia dentária para de Odontologia. Há dois conteúdos acrescidos no decreto de 1884: o de Higiene Dentária e o de Prótese Dentária. Esses conteúdos já haviam constado na conformação direcionada à realização de exames de regulação em 1856, removidos em 1879, retornando, novamente, em 1884. É como se, na letra da lei, a cirurgia dentária fosse tomada como sinônimo de Odontologia.

Mas, foi na Primeira República que se completou a autonomia do ensino da Odontologia em relação ao da Medicina no Brasil, especialmente com os Decretos publicados em $1891^{18}$ e $1893^{19}$, que orientam a organização das Faculdades de Medicina. Seguindo a pista de políticas voltadas à organização do ensino superior e ao ensino da Medicina, por conseguinte, ao da Odontologia, verifica-se de que modo essa autonomia se consolidou, consolidando, ao mesmo tempo, a identidade do cirurgião-dentista e a clínica por ele desempenhada.

Em relação às propostas curriculares das políticas direcionadas à organização do ensino da Odontologia, editadas anteriormente, em $1879^{14} \mathrm{e}$ $1884^{15}$, há a diminuição de uma série no Curso de Odontologia e a supressão das matérias básicas de Física, Química e Fisiologia. Por outro lado, a criação da matéria de Clínica Odontológica. Porém, pelo que se pode depreender do texto da legislação quanto à dinâmica de funcionamento da disciplina de Clínica Odontológica, conclui-se que essa matéria estava extremamente associada ao ensino da Prótese Dentária.

Sobre o funcionamento físico do Curso de Odontologia preconizado pelos Decretos de 1891 e 1893, constatam-se constantes mudanças nas diretrizes políticas editadas ao final do Império nas denominações do laboratório do Curso de Odontologia. O nome do laboratório já havia mudado por três vezes (Operações e Prótese Dentária, Cirurgia e Prótese Dentária e apenas Prótese Dentária). Mudou mais uma vez, no Decreto de 1891, para Laboratório de Odontologia, vinculado a um Instituto de Odontologia recém-criado. Com a criação do Instituto Odontológico delimitou-se, oficialmente, no âmbito de funcionamento da Faculdade de Medicina, uma área específica para o ensino da Odontologia, ou mais especificamente da Prótese 
Dentária. Quanto aos responsáveis pela condução das atividades de ensino nesse espaço, além do preparador do curso incumbido do ensino da Prótese Dentária, deveria haver também, no Curso de Odontologia, um preparador de Clínica Odontológica $^{18}$. O Preparador da Clínica Odontológica deveria se responsabilizar pelas disciplinas de Patologia e Terapêutica Dentária, sendo admitidos Cirurgiões-Dentistas, por meio de concurso e nomeação da Congregação da Faculdade de Medicina, para os dois $\operatorname{casos}^{19}$.

O Decreto de 1893 propunha o tempo de duração para que se efetuassem as matérias no curso de Odontologia, evidenciando uma valorização do componente prático do curso. Cada matéria básica deveria ser ministrada em um mês, a Patologia e a Terapêutica Dentária em seis meses, e apenas a Clínica e a Prótese Dentária no transcorrer de todo o curso. É possível relacionar este formato prático das grades curriculares propostas pelas políticas nesse período à influência das filosofias positivistas.

Logo no início do Século $\mathrm{XX}$, em relação às orientações de organização do Curso de Odontologia contidas na Lei Rivadávia de 1911, dois destaques podem ser feitos: a existência de um artigo norteando que as matérias da $1^{a}$ Série constituem um exame básico e as da $2^{a}$ Série o exame final $^{20}$. Nas proposições iniciais do ensino da Odontologia conformou-se a divisão entre ciclo básico e profissional, adequando-se as estruturas do ensino e das práticas profissionais em sua articulação com o ensino médico. Representam a dificuldade que se estabeleceu, desde a emergência do ensino da Odontologia, com a articulação entre as práticas profissionais e o ensino básico.

O conteúdo de Técnica Odontológica surgiu nos currículos dos decretos de $1911^{20}$ e $1915^{21}$, situando-se na segunda série ao lado da matéria Clínica Odontológica. Nas diretrizes de 1911, a matéria Técnica Odontológica contém a instrução "exercícios em manequins".

Nas diretrizes políticas que organizavam os cursos de Odontologia, o laboratório foi o primeiro lugar que se estabeleceu para o ensino da Odontologia. Lá deveria se ensinar Cirurgia e Prótese Dentária. É somente no transcorrer da implantação e especialização deste ensino, que essa estrutura se subdivide em duas, a Clínica e a Técnica: para a primeira, o gabinete odontológico; a segunda permanecia no laboratório. Mas, até onde vai uma e onde começa a outra? Detalhes do ofício e do ensino que desafiam até hoje a profissão.

A reforma do ensino Rocha Vaz, em 1925, selou oficialmente a autonomia institucional do Curso de Odontologia que vinha sendo configurado desde o Império ${ }^{22}$. Em seu artigo trinta e seis, o decreto define quais cursos deveriam ser considerados de nível superior, situando a Odontologia e a Farmácia ao lado das outras áreas que já possuíam suas Faculdades próprias desde o Império: o Direito, a Engenharia e a Medicina. O Curso de Odontologia, deveria ser ministrado em três anos. Apenas a legislação do ensino referente ao ano de $1884^{15}$ havia proposto esse tempo de duração. O aumento de carga horária (um ano) não promoveu diversificação de matéria, mas aumentou o tempo das matérias básicas do currículo, mantendo-as em sua maioria com o mesmo nome: Anatomia, Histologia, Fisiologia e Patologia, com exceção do surgimento da Microbiologia. Por outro lado, com o conteúdo de Metalurgia, a química retornou ao currículo, c o m o havia sido proposto apenas nas primeiras proposições curriculares das reformas de Leôncio Carvalho em $1879^{14}$ e $1884^{15}$. 
Analisando a forma como as matérias básicas ou gerais foram sendo propostas nos diferentes currículos dos Cursos de Odontologia analisados, verifica-se que as reformas de influência positivista reservavam menos tempo para os conteúdos básicos ou gerais. Houve também, constantes mudanças nas denominações e localizações dessas matérias nas grades curriculares de seriação. A maioria das inconstâncias relacionou-se à necessidade de indicação da delimitação do estudo, se deveria ser geral ou local e, neste caso, se deveria ser da cabeça, da boca ou apenas dos dentes, ou até mesmo microscópico. Isto pode ser interpretado como uma dificuldade na compreensão sobre o modo como os conteúdos gerais poderiam ou deveriam ser incorporadas na formação do cirurgião-dentista. A mesma inconstância não se apresenta, pelo menos com a mesma intensidade, no ciclo final ou profissionalizante, como no caso da Prótese Dentária, por exemplo.

\section{CONSIDERAÇÕES FINAIS}

Dessa forma, e como era de se esperar, as proposições curriculares que definiram a emergência e autonomia do ensino da Medicina continuam identificando as práticas discursivas dos dentistas ainda hoje, mais de cem anos após a publicação e promulgação das primeiras legislações, que produziram esses efeitos. Daí que a história seja um a priori para dizer de que modo chegamos a ser o que somos.

Pode-se afirmar que não apenas a emergência do ensino da Odontologia ao final do Império, mas também a implementação da sua autonomia na Primeira República, foram acontecimentos constituídos no interior da trama política e social desenhada pelos movimentos positivistas brasileiros em torno do ensino livre, que marcaram fortemente o cenário político brasileiro nesse período.

Debater os padrões curriculares que as diretrizes políticas impuseram ao ensino da Odontologia brasileiro, no seu percurso de institucionalização, permitiu identificar de que modo o ensino da Odontologia foi se consolidando em separado da Medicina. Essa análise foi possível de ser realizada não somente através da identificação dos conteúdos das diretrizes curriculares, mas verificando-se, também, a delimitação dos espaços para o ensino das práticas profissionais, a constituição dos quadros funcionais de professores, e o próprio tempo de duração dos cursos.

A ausência da matéria de clínica dentária ou odontológica nas proposições curriculares marcou a emergência do ensino da Odontologia no final do Império. Essa ausência assinala um modo de compreensão do funcionamento da prática odontológica e das práticas discursivas de autores, no início do século XX. Nesse percurso, a clínica odontológica se aproximou e até se confundiu com a técnica e com a prótese dentária. Foi uma perspectiva que o estudo procurou privilegiar, a de identificar, no percurso de instituição das diretrizes curriculares, os modos de compreender e de atuar da clínica odontológica.

Relatório sobre o Ensino Odontológico Brasileiro realizado pela $\mathrm{ABENO}$, no ano de $1961^{22}$, avaliou nos cursos de Odontologia brasileiros, que as cadeiras de clínica odontológica e prótese dentária eram as mais organizadas, mas havia muitas dificuldades nas cadeiras consideradas básicas (compostas pelo ensino da Anatomia, Fisiologia, Histologia e Microbiologia) e, nas denominadas de Higiene e Odontologia Legal, cadeiras que conformarão o campo de estudos da Odontologia Social. 
O presente estudo demonstrou que a separação das práticas odontológicas das médicas produziu condições de possibilidade para o nascimento da profissão odontológica e esse acontecimento representou, para a Odontologia, não apenas prescindir dos conhecimentos e procedimentos intrínsecos à clínica médica, mas direcionou, também, seu contexto científico de criação. As políticas voltadas para a formação do cirurgião-dentista brasileiro foram, portanto, constituidoras de práticas odontológicas, de identidades profissionais e de um modo de entender a saúde bucal

Os dados aqui analisados foram produzidos na pesquisa realizada na tese de doutorado da autora publicada no livro Da Autonomia da Boca: Constituição do Ensino da Odontologia no Brasil $^{24}$.

\section{ABSTRACT \\ From practice to teaching: the constitution of the Dental clinic}

The objective of this study is to analyze the relationship established between professional practices and Dental education in the establishment of the Dental clinic in the context of its approach and separation of medicine in Brazil. Different documentary sources were analyzed: legislation, institutional records, journalistic and legal documents, government reports, as well as technical and historical books in the field of Dentistry. The intention is to use history to problematize the actuality. It was verified that the dental clinic, in its constitution process, approached and even became confused with the technique and the dental prosthesis, both in professional practices and in teaching. A way of working in the discursive practices of professionals, in the early twentieth century, separated dentistry from medicine and represented not only the lack of knowledge and procedures intrinsic to medical practice, but also directed its scientific and creative context. The process of institutionalizing dentistry teaching separately from that of medicine in Brazil played a preponderant role.

Descriptors: Teaching. Dentistry. History. Oral Health. Dental Clinics.

\section{REFERÊNCIAS}

1. Foucault M. O nascimento da clínica. 5. ed. Rio de Janeiro: Forense Universitária,1998. $241 \mathrm{p}$.

2. Botazzo C. Da arte dentária. São Paulo: Hucitec; Fapesp, 2000.

3. Patiño GA. Algo de historia... el cirujano Pierre Fauchard. Rev Fed Odontol Colomb. 1985;34(151):117-23.

4. Gayon J. Epistemologia da medicina. In: Russo M, Caponi S. Estudos de filosofia e história das ciências biomédicas. São Paulo: Discurso Editorial, 2006. p.39-63.

5. Rose N. Medicine, History, and The Present. In: Jones C, Roy P. Reassessing Foucault: power, medicine and the body. Routledge, 1994.

6. Souza AC. Impressões dos Estados Unidos. Rio de Janeiro: Papelaria Vênus, 1927. 182 p.

7. Lima, C. Da odontologia a medicina. Porto Alegre: Oficina Gráficas do "Centro da boa Imprensa", 1929.

8. Schifino L. Infecção focal de origem bucal. Rev Esc Odontol Porto Alegre. 1956;2(1):165-78.

9. Brito JHM. Faculdade de Odontologia: cem anos de História 1898-1998. Porto Alegre: Faculdade de Odontologia da UFRGS, 1998. $127 \mathrm{p}$. 
10. Lima C. Odontologia e medicina. Porto Alegre: Edição da Livraria do Globo, 1939.

11. Cunha ES. História da odontologia no Brasil (1500 - 1900). 2. ed. Rio de Janeiro: Editora Científica, 1952. 288 p.

12. Souza AC. Manual odontológico: prótese dentária dentaduras. 7. ed. Juiz de Fora : Estabelecimento Gráfico Dias de Cardoso, 1932. 502 p.

13. Carvalho AD. Souza AC. Manual Odontológico: clínica odontológica (Téchnica). 5 ed. Juiz de Fora, MG: Estabelecimento Gráfico Dias de Cardoso \& C., 1917.

14. Brasil. Decreto $\mathrm{n}^{\circ} 7.247$, de 19 de abril de 1879. Reforma o ensino primário e secundário no município da Corte e o superior em todo o Império. Collecção das Leis do Império do Brasil de 1879. Rio de Janeiro: Typografia Nacional, 1880. p. 196-215, Parte 2. [Acesso em 6 ago. 2007]. Disponível em: http:// www2.camara.gov.br/legislacao/publicacoes/ doimperio.

15. Brasil. Decreto $n^{\circ} 9.311$, de 25 de outubro de 1884. Dá novos estatutos às Faculdades de Medicina. Collecção das Leis do Império do Brasil de 1884. Rio de Janeiro: Typografia Nacional, 1885. p. 478-552, v. 1. [Acesso em 6 ago. 2007]. Disponível em: http://www2. camara.gov.br/legislacao/publicacoes/doimpe rio.

16. Edler FC. As reformas do ensino médico e a profissionalização da medicina da corte do Rio de Janeiro - 1854-1884. 1992. 275 f. Dissertação (Mestrado em História) Departamento de História, Universidade de São Paulo, São Paulo, 1992.

17. Brasil. Lei Orçamentária $n^{\circ} 3.141$, de 30 de outubro de 1882. Fixa a despesa Geral do Império para os exercícios de 1882 -1883 e
1883-1884 e dá outras providências. Collecção das Leis do Império do Brasil de 1882. Rio de Janeiro:Typografia Nacional, p. 105-125. [Acesso em 6 ago. 2007]. Disponível em: http://www2.camara.gov.br/ legislacao/publicacoes/doimperio.

18. Brasil. Decreto $\mathrm{n}^{\mathrm{o}} 1.270$, de 10 de janeiro de 1891. Reorganiza as Faculdades de Medicina dos Estados Unidos do Brazil. Decretos do Governo Provisório da República dos Estados Unidos do Brasil de 1891. Rio de Janeiro: Imprensa Nacional, 1891. p. 193-228, v. 1. [Acesso em 6 ago. 2007]. Disponível em: http://www2.camara.gov.br/legislacao/public acoes/republica.

19. Brasil. Decreto ${ }^{\circ} 1.482$, de 24 de julho de 1893. Aprova os regulamentos para as Faculdades de Medicina da República. Coleção das Leis da República dos Estados Unidos do Brasil de 1893. Rio de Janeiro: Imprensa Nacional, 1894. Atos do Poder Executivo, p. 478-521. [Acesso em 6 ago. 2007]. Disponível em: http://www2. camara.gov.br/legislacao/publicacoes/republi ca.

20. Brasil. Decreto $n^{\circ} 8.661$, de de 05 de abril de 1911. Aprova o Regulamento das Faculdades de Medicina. Coleção das Leis da República dos Estados Unidos do Brasil de 1911. Rio de Janeiro: Imprensa Nacional, 1911. p. 527-542.

21. Brasil. Decreto $n^{\circ} 11.530$, de 18 de março de 1915. Reorganiza o ensino secundário e superior da república. Coleção das Leis da República dos Estados Unidos do Brasil de 1915. Rio de Janeiro: Imprensa Nacional, 1915. p. 1107-1135. [Acesso em 6 ago. 2007]. Disponível em: http://www2.camara.gov.br/ legislacao/publicacoes/republica.

22. Brasil. Decreto ${ }^{\circ}$ 16.782-A, de 13 de janeiro 
de 1925. Estabelece o concurso da União para a difusão do ensino primário, organiza o Departamento Nacional do Ensino, reforma o ensino secundário e o superior e dá outras providências. Coleção das Leis da República dos Estados Unidos do Brasil de 1925. Rio de Janeiro: Imprensa Nacional, 1926. p. 20-94, v. 2. [Acesso em 6 ago. 2007]. Disponível em: http://www2.camara.gov.br/legislacao/public acoes/republica.
23. Guimarães PJR. O ensino odontológico no Brasil. (Série Levantamento e Análises, 25). Rio de Janeiro: Capes, 1961. $44 \mathrm{p}$.

24. Warmling CM. Da Autonomia da Boca: Constituição do Ensino da Odontologia no Brasil. Porto Alegre: Editora Ufrgs, 2016. $150 \mathrm{p}$.

Correspondência para:

Cristine Maria Warmling

e-mail: cristinewarmling@yahoo.com.br Rua Ramiro Barcelos, 2492 - Santa Cecilia 90035-003 - Porto Alegre/RS 